$4^{\circ}$ Epreuve de la réductase avec une solution de bleu de méthylène acidifiée par l'acide lactique de telle sorte qu'i y ait $10 \mathrm{gr}$. d'acide lactique par $1.000 \mathrm{gr}$. de caséine.

La caséine acidifiée à $1 \%$ s'est montrée encore mauvaise, mais elle présentait beaucoup moins de colonies que l'essai-témoin ; par contre les caséines acidifiées à 5 et $10 \%$ ne présentaient aucune tache.

Si l'emploi de l'acide lactique n'a pas d'inconvénient pour les matières plastiques, il serait donc possible aux fabricants d'éviter les fermentations qui les gênent en mouillant leurs caséines, non avec de l'eau pure, mais avec de l'eau acidulée, de telle sorte que celle-ci introduise dans la masse une quantité d'acide lactique qu'ils détermineraient facilement avec précision, mais qui, d'après nos expériences, doit être comprise entre 1 et $5 \%$.

\title{
UNE AMÉLIORATION IMPORTANTE DU BOUCHON ANAÉROBIE AU PYROGALLOL.
}

\author{
par W. DORNER et W. RITTER
}

de l'Etablissement fédéral d'industrie laitière et de bactériologie, Liebefeld-Berne.

(Directeur : M. le Prof. Dr R. BurRr.)

L'emploi de mélanges de pyrogallol et d'alcalis pour absorber l'oxygène dans des cultures de bactéries a été décrit en premier lieu par Buchner [1]. Selon une communication particulière du Prof. Orla-Jensen, Stribolt [2], au Danemark, puis Wright [3], aux Etats-Unis, ont développé un procédé s'appliquant individuellement aux tubes de culture. BuRRI [4] a ensuite amélioré ce procédé en mettant les réactifs pour l'absorption de l'oxygène sur un bouchon d'ouate hydrophile introduit spécialement dans ce but. On a remarqué depuis, sans savoir pourquoi, qu'un grand nombre d'espèces de microbes anaérobies se développaient mal ou ne venaient pas du tou't en cultures superficielles sous ce bouchon.

C'est un travail de RockWELL et HighBERGER [5] qui a donné la clef du mystère. Ces auteurs ont en effet prouvé que les microbes ont besoin d'acide carbonique pour vivre. Or, les bouchons anaérobies mentionnés n'absorbent pas seulement l'oxygène ; ils absorbent aussi l'acide carbonique, par suite de l'excès d'alcali employé.

Des essais que nous avons entrepris ont confirmé entièrement les résultats de Rock weLL et HigHBERGER. Comme eux, nous avons pu empêcher complètement le développement de certaines espèces microbiennes en les cultivant sur les milieux usuels dans un réci- 
pient fermé qui contenait en outre un peu de soude caustique. Les lactobacilles et les streptocoques thermophiles du fromage ne se développent pas du tout dans une atmosphère débarrassée de son acide carbonique.

Etant donné cela, nous avons cherché le moyen d'empêcher l'absorption de l'acide carbonique par le bouchon anaérobie. Des expériences confirmant les indications de HALL [6] ont démontré que ce résultat peut être atteint en augmentant la quantité d'acide pyrogallique relativement à celle de la soude caustique. HALL [6] emploie l'acide pyrogallique en cristaux et y ajoute de la soude caustique. Il est obligé de renverser les tubes pendant l'incubation pour éviter que le liquide absorbant ne coule sur la gélose. A part le manque de sécurité absolue, ee procédé a l'inconvénient de ne pas pouvoir être employé pour des cultures en milieux liquides. Dans certains cas la gélose peut aussi se détacher du verre et glisser vers le bouchon lorsque les tubes sont renversés pour l'incubation.

En poursuivant la question nous avons trouvé que la solution la plus simple était de remplacer la soude ou la potasse caustiques employées pour le bouchon selon WRIGHT-BURRI par du carbonate de soude ou du carbonate de potasse. De cette manière on assure l'absorption de l'oxygène sans enlever l'acide carbonique. On provoque au contraire une libération de $\mathrm{CO}^{2}$ dans le tube.

Il découle d'une publication de Kovacs-Zorkoczi [7] qu'une molécule d'acide pyrogallique peut fixer environ 2 atomes et demi d'oxygène. Par conséquent, $1 \mathrm{~cm}^{3}$ d'une solution à $20 \%$ d'acide pyrogallique absorberait environ $44 \mathrm{~cm}^{3}$ d'oxygène, soit la quantité contenue dans $220 \mathrm{~cm}^{3}$ d'air environ.

Nous avons constaté que l'absorption de l'oxygène par le mélange de pyrogallol et de carbonate de soude se fait un peu moins rapidement qu'avec le mélange pyrogallol-soude caustique. Ce n'est pas un inconvénient, au contraire.

Nous avons éprouvé entre autres notre nouveau bouchon anaérobie comparativement à l'ancien sur des stries sur gélose des microbes suivants : lactobacilles et streptocoques du fromage, Bac. amylobacter, Bac. putrificus, bactéries propioniques, ete. Tous ces microbes nous ont donné des cultures vigoureuses en surface sous notre bouchon, tandis qu'd l'exception du Bac, putrificus, elles ne se développaient pas du tout sous l'ancien. Le Bac. putrificus semble moins exigeant quant à l'acide carbonique, car il s'est développé; sa croissance était cependant moins bonne sous l'ancien bouchon que sous le nouveau. Il se pourrait aussi que l'action protéolytique très forte qui lui est propre soit suffisante pour produire assez de $\mathrm{CO}^{2}$ pour permettre un léger développement. 


\section{RÉSUME ET MODE D'EMPLOI}

Les bouchons anaérobies d̀ base d'acide pyrogallique et de soude ou de potasse caustiques utilisés jusqu'ici absorbent l'anhydride carbonique dans l'espace où la culture se trouve et empêchent par là un grand nombre de microbes sensibles à ce point de vue de se développer.

Le nouveau bouchon que nous avons proposé et pour lequel on emploie une solution saturée de carbonate de soude au lieu de soude caustique n'a pas cet inconvénient.

Après ensemencement des tubes de culture, on le prépare comme suit :

$1^{\circ}$ On coupe le bouchon d'ouate au ras du tube.

$2^{\circ}$ On flambe, puis enfonce ce qui en reste jusqu'à ce qu'il touche presque le bord supérieur du milieu de culture.

$3^{\circ}$. On met un nouveau bouchon d'ouate hydrophile dans le tube.

$4^{\circ}$ On ajoute, selon la grandeur du tube, 1 ou $1 / 2 \mathrm{~cm}^{3}$ de solution d'acide pyrogallique à $20 \%$, puis la même quantité de solution saturée de carbonate de soude (1) sur la ouate hydrophile.

$5^{\circ}$ On ferme immédiatement le tube avec un bouchon de caoutchouc mouillé, pour assurer une bonne étanchéité.

\section{BIBLIOGRAPHIE.}

[1] H. Buchner. Z $b l$. Bakter., 4, 149 (1888).

[2] Stribolt. Cité par J. Salomonsen in Bakteriologisk Teknik, p. 110. Copenhague, 1894.

[3] Wright. Zbl. Bakter. I. Orig., 29, 61 (1901).

[4] J. Kürsteiner. Zentrbl. Bakt. II, 19, 23 (1907).

[5] Rockwell et Highberger. J. Inf. Dis., 40, 438 (1927).

[6] I. C. Hall in "Pure Culture Study of Bacteria ", Society of American Bacteriologists, p. III/32/6. Traduction allemande de W. Dorner, 1933. Schaper, Hannover.

[7] E. Kovacs-Zorkoczi. Bioch. Ztschr., 162, 161 (1925).

\section{UN MOdE SIMPLE, PRATIQUE ET RATIONNEL DE PAIEMENT DU LAIT EN FROMAGERIE.}

$$
\text { par }
$$

\section{E. VAILLANT}

I'ıgénieur agronome.

I. LA CONNAISSANCE DU TAUX DE MATIÈRE GRASSE D'UN LAIT SUFFit-ELLE A DÉterminer LA VALEur RÉLLE DE CE LAIT ?

L'industrie laitière peut, incontestablement, à l'heure actuelle,

(1) La solution saturée s'obtient en dissolvant environ $25 \mathrm{gr}$. de carbonate de soude anhydre ou $50 \mathrm{gr}$. de eristal dans $100 \mathrm{~cm}^{3}$ d'eau. 